\title{
Outcomes of the Special Issue on Approaches to hazard evaluation, mapping, and mitigation
}

\author{
G. G. R. Iovine ${ }^{1}$, J. Huebl ${ }^{2}$, M. Pastor ${ }^{3}$, and M. F. Sheridan ${ }^{4}$ \\ ${ }^{1}$ Istituto di Ricerca per la Protezione Idrogeologica, Consiglio Nazionale delle Ricerche, Cosenza, Italy \\ ${ }^{2}$ Institute of Mountain Risk Engineering, University of Natural Resources and Life Sciences, Wien, Austria \\ ${ }^{3}$ Applied Mathematics and Computer Science, Madrid, Spain \\ ${ }^{4}$ Center for GeoHazards Studies, University at Buffalo, Buffalo, NY, USA
}

Natural and human-related disasters cause numerous casualties and large economic losses every year in different parts of the World. The increasing number of natural and manmade disasters with human and economic consequences underscores the need for better approaches to hazard evaluation and risk reduction. Single or multiple natural triggers and man-made causes can result in disasters. Disasters resulting from multiple natural (NAT) and technological (TECH) triggers are particularly complex to investigate. They may independently affect an area simultaneously (through a combination of the effects of the individual hazards), or may evolve through complex and interrelated chains of events (e.g. domino effects) through: (i) a concatenation of technological incidents (TECH-TECH), (ii) technological incidents capable of triggering potentially harmful natural processes and events (TECH-NAT), (iii) natural processes capable of causing technological incidents and disasters (NAT-TECH), and (iv) natural events and processes that can cause other damaging natural events (NAT-NAT).

An example of a complex NAT-TECH disaster was the 11 March 2011, Tôhoku, Japan, 9.0 mega thrust earthquake. With an epicentre approximately $70 \mathrm{~km}$ east of the Oshika Peninsula, this was among the five largest earthquakes on record in the world. The earthquake triggered a destructive tsunami, with waves up to $39 \mathrm{~m}$ in height that travelled up to $10 \mathrm{~km}$ inland. In addition to loss of life (>25000 fatalities and $>5000$ injured people), and the destruction of 125000 buildings and numerous infrastructures, the tsunami caused multiple nuclear accidents, with a level-7 accident at the Fukushima I nuclear power plant. Preliminary estimates of the total economic cost exceed $€ 210$ billion, making this complex NAT-TECH disaster the most expensive ever observed.

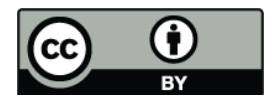

Correspondence to: G. G. R. Iovine (giulio.iovine@irpi.cnr.it)
Single disasters remain difficult to understand and predict. Multiple disasters, caused by complex combinations and interactions of natural and technological hazards, are even more complex to understand and forecast, and pose a major challenge to scientists, engineers, and planners. The special issue of NHESS on "Approaches to hazard evaluation, mapping, and mitigation" derives from oral and poster contributions presented at seven scientific sessions organized during four international conferences in Europe and Asia in 2009 (the complete list of sessions is given in the Appendix). The collective aim of the seven sessions was to provide opportunities for multidisciplinary discussions on innovative methods and techniques for single and multiple hazard evaluation, detection and mapping, and for the design of risk mitigation strategies. Key topics discussed at the meetings were mathematical and physical modelling of natural and technological hazards, model calibration and validation, and model sensitivity.

This special issue comprises ten papers, including three papers discussing landslide susceptibility, four papers dealing with geotechnical problems and related hazards, and three papers discussing the hazards posed by tsunami and land subsidence caused by mining activity, and computer simulations to model the evacuation of the population prompted by volcanic events. In the following sections we summarize briefly the main findings of the individual papers.

The three papers discussing landslide susceptibility focus on different types of landslides, ranging from shallow mudslides to deep-seated phenomena (Mancini et al., 2010), to shallow landslides (Vieira et al., 2010), to debris flows (Kappes et al., 2011).

Mancini et al. (2010) used a logistic regression classification method to prepare a susceptibility map for an area of $1300 \mathrm{~km}^{2}$ in the Apulian Apennines, Italy. Landslides are abundant in the area and have repeatedly threatened historical settlements. The model was prepared by generating a regularly-spaced $40 \times 40 \mathrm{~m}$ digital elevation model

Published by Copernicus Publications on behalf of the European Geosciences Union. 
derived from photogrammetric processing of aerial images (at 1:10000 scale), using landslide information mapped at 1:5000 scale and obtained from fieldwork, analysis of aerial images and historical data; lithology and land cover were available at 1:100 000 and 1:50000 scale, respectively. The performance of the landslide susceptibility zonation, determined by comparison against the landslide inventory, revealed that $85 \%$ of the areas classified as susceptible by the model corresponded to areas where landslides were known.

Vieira et al. (2010) modelled the occurrence of shallow landslides in the Copebràs basin, a $3.6 \mathrm{~km}^{2}$ catchment in the Serra do Mar mountain range, Brazil, using the Transient Rainfall Infiltration and Grid-Based Regional SlopeStability Analysis code (TRIGRS, Baum et al., 2002). Multiple scenarios were investigated considering different values for the mechanical and hydrological model parameters. Due to the lack of detailed information on spatial variability of soil properties, homogeneous conditions were considered. Two groups of scenarios were simulated: (i) soil cohesion and unit weight values were assumed under saturated conditions; (ii) different values of cohesion and unit weight were used under unsaturated conditions. For each scenario, three subgroups were then considered, characterized by different values of soil thickness and by the same initial depth of water table. In all the simulations, constant values of angle of internal friction, of steady infiltration rate, of hydraulic diffusivity, and of vertical hydraulic conductivity of saturated soil were assumed as well. Hydraulic properties of the soil were assumed to be uniform with depth (cf. Iverson, 2000). Susceptibility maps were therefore generated considering the minimum value of the Safety Factor computed for each cell. Results were tested against a map showing landslide scars caused by an historical rainfall event. To quantify the tests, two indices were used: the Scars Concentration index, and the Landslide Potential index. A good agreement between the modelled landslide scenarios and the landslide map was obtained. The proposed approach proved useful for the prediction of shallow landslides over large areas.

Kappes et al. (2011) completed a regional debris-flow susceptibility assessment for the Barcelonnette area, France. For this purpose, the authors used a digital representation of the topographic surface (a DEM), empirical rules for the identification of the potential debris-flow source areas, and the empirical "angle of reach" concept (Corominas, 1996) for the computation of the run-out of the potential debris flows. Multiple scenarios were considered, including a worst-case scenario, and scenarios for high, medium, and low frequency debris-flow events. Comparison between the susceptibility models and maps showing past debris-flow events revealed that the susceptibility zonation was reasonable, but dependent on the accuracy of the available DEM.

Geotechnical investigations discussed in the special issue include (i) a site-specific study of a single, deep-seated landslide (Iovine et al., 2010), (ii) an investigation of the mechanical behaviour of a pyroclastic deposit (Scotto di Santolo et al., 2010), (iii) the assessment of the liquefaction potential of sandy soils (Sen and Akyol, 2010), and (iv) the decay of the material properties of soft rocks caused by weathering (Aziz et al., 2010).

Iovine et al. (2010) analysed the activation phase of a large debris slide that threatened the village of San Benedetto Ullano, Calabria, Italy. The analysis was based on measurements obtained from a complex network of manual and automatic instruments deployed immediately after the onset of the landslide movement. The information obtained from the network was used in an emergency management decision support system. During a short period of dormancy, the geological scheme of the slope was refined based on the data collected through a set of boreholes equipped with inclinometers and piezometers. A parametric limit equilibrium analysis was carried out to explore the stability conditions of the slope, and to understand the role of the water table. The interpretation of the kinematics of the landslide based on the analysis of the surface and sub-surface deformation was confirmed by limit equilibrium analysis. The authors concluded that activation of the landslide is expected in the middle portion of the slope when the groundwater approximates the ground surface in the same area.

To perform their experiments to investigate the mechanical behaviour of a debris flow that originated from pyroclastic deposits, Scotto di Santolo et al. (2010) used a standard rotational rheometer with two different geometries. The influence of solid concentration and grain size distribution was studied. Soil mixtures with varying proportions of water were tested. All mixtures showed a non-Newtonian fluid behaviour, with yield stress increasing with solid volumetric concentration and decreasing with sand fraction. Yield stress proved to be a key parameter to predict the post-failure behaviour of the volcanic debris flow. The result indicates that a small variation of the solid fraction in the mixture, e.g. due to rainfall, results in a reduction of the static yield stress, and in a rapid flow. This is in agreement with field observations.

To determine the liquefaction potential of sandy soils, Sen and Akyol (2010) constructed a genetic algorithm model and used in situ data obtained from Cone Penetration Tests (CPT) derived from 242 case studies from different regions of the world taken from literature. A genetic algorithm (GA) was used for the selection of the model parameters and the assessment of the soil liquefaction potential, expressed by the Liquefaction Index. Different estimation functions were considered and applied to training (200 cases) and validation (42 cases) datasets, the latter obtained by random selection. The proposed GA-based approach for estimating the liquefaction potential based on Liquefaction Index and CPT data resulted in good agreement with expected soil behaviour.

Aziz et al. (2010) investigated the time-dependent granular decomposition of soft rocks caused by weathering and leading to a reduction of the mechanical properties of the rocks. Monotonic torsional shear tests were conducted on crushed material, under fully saturated and dry conditions. Results 
were compared with tests on the standard Toyoura sand. The authors found that saturated conditions accelerated granular decomposition and loss of strength with time. Significant volumetric loss during consolidation and monotonic loading of saturated samples and drastic loss of strength upon submergence were observed. The changes of the mechanical properties can be critical to embankments constructed with soft rocks.

The remaining three papers discuss three different hazards and their consequences. Two of them discuss natural hazards, tsunami (Tselentis et al., 2010) and volcanic activity (Marrero et al., 2010), and one discusses human-induced subsidence caused by mining activity (Akcin et al., 2010).

Akcin et al. (2010) used consolidated DInSAR techniques and C-Band Radarsat images to measure the surface deformations caused by extensive underground mining activity in the Zonguldak Hardcoal Basin, Turkey. Surface deformation maps for the period July 2005-October 2006 were integrated in a GIS environment with mining production maps, and very-high resolution satellite images. Analysis of available information showed that the mining-induced surface deformation affected public and private buildings and at least twelve kilometres of roads.

Tselentis et al. (2010) adopted a scenario-based approach to analyse the hazard posed by a potential tsunami associated to the Ionian fault system in the Mediterranean Sea. Realistic faulting parameters related to four probable tsunamogenic sources were used to model the expected co-seismic surface deformation, which was translated directly to the water surface, and used as initial condition for modelling the propagation of a tsunami. Tsunami propagation snapshots and mareograms for the four seismic sources were used to estimate the maximum expected amplitudes and arrival times of waves at eleven tourist resorts along the Ionian coast, Italy. Results showed that one of the examined sources is capable of producing 4-m high waves at the considered touristic resorts, posing a severe threat to the population.

Lastly, Marrero et al. (2010) presented the Variable Scale Evacuation Model (VSEM), a computer model for the simulation of evacuations of the population prompted by volcanic events. VSEM allows optimizing the evacuation process by considering different strategies and impact scenarios. The model calculates the time required for a complete evacuation based on the amount and type of behaviour of the population, the location, the type and characteristics of the road network, and discovers critical points along the evacuation network (cf. e.g. Chakraborty et al., 2005; Guanquan et al., 2006).

In summary, although there were a large number (161) of conference presentations, only a small subset of manuscripts (about $10 \%$ ) was actually received by the deadline. Of these, ca. $60 \%$ survived the review phase. Most of the received papers focused on slope stability issues, whereas only few dealt with other phenomena - from tsunami to land subsidence to evacuation of population threatened by volcanic eruptions. In spite of the obvious interest of many papers in documenting case studies and specific difficulties in applying available tools and methods of analysis and modelling, more effort is still needed to define quality standards for the procedures that are applied in hazard evaluation, mapping, and mitigation.

\section{Appendix A}

The special issue collects studies originally presented at four international conferences held in 2009 in Europe and Asia, including:

- two sessions at the European Geosciences Union (EGU), General Assembly 2009, Vienna, 1924 April 2009, on Modelling and simulation of dangerous phenomena, and innovative techniques for hazard evaluation, mapping, mitigation (session NH11.2, convened by G. Iovine, J. Huebl, M. F. Sheridan, M. Pastor, A. C. Costa, H. Kantz, A. Witt), and on Landslide Forecasting (session NH4.14/HS11.6, convened by F. Guzzetti, G. Iovine, and M. Parise),

- a session organized for the at 18th World IMACS (International Association for Mathematics and Computers in Simulation) Congress and MODSIM09 International Congress on Modelling and Simulation, Cairns, Australia, 13-17 July 2009, on Modelling and simulation of dangerous phenomena, and innovative techniques for hazard evaluation (session G3, convened by G. Iovine, M. Pastor, and M. F. Sheridan),

- two sessions at the Asia Oceania Geosciences Society 6th Annual General Assembly, Singapore, 11-15 August 2009, on Modelling and simulation of dangerous phenomena, and innovative techniques for hazard evaluation, mapping, mitigation (session IWG01-04, convened by G. Iovine, M. Pastor, H. Miyamoto, Y. Shi, J. B. Rundle, D. A. Yuen, and H. Zhang), and on Natural hazards - processes, impacts and adaptation (session IWG03, convened by J. P. Terry and G. Iovine),

- two sessions organized at the VII Italian Forum on Earth Science, GEOITALIA 2009, held in Rimini, Italy, 911 September 2009, on Innovative approaches for landslide hazard evaluation and risk mitigation (session B4, convened by G. Iovine, M. Parise, and P. Reichenbach), and on Landslide forecasting (session B7, convened by F. Guzzetti, G. Iovine, and M. Parise). 


\section{References}

Akcin, H., Kutoglu, H. S., Kemaldere, H., Deguchi, T., and Koksal, E.: Monitoring subsidence effects in the urban area of Zonguldak Hardcoal Basin of Turkey by InSAR-GIS integration, Nat. Hazards Earth Syst. Sci., 10, 1807-1814, doi:10.5194/nhess-101807-2010, 2010.

Aziz, M., Towhata, I., Yamada, S., Qureshi, M. U., and Kawano, K.: Water-induced granular decomposition and its effects on geotechnical properties of crushed soft rocks, Nat. Hazards Earth Syst. Sci., 10, 1229-1238, doi:10.5194/nhess-10-12292010, 2010.

Baum, R. L., Savage, W. Z., and Godt, J. W.: TRIGRS: A FORTRAN program for transient rainfall infiltration and grid-based regional slope-stability analysis, USGS, Colorado, Open-file Report 02-424, 35 pp., 2002.

Chakraborty, J., Tobin, G. A., and Montz, B. E.: Population evacuation: assessing spatial variability in geophysical risk and social vulnerability to natural hazards, Natural Hazards Rev., 6(1), 2333, 2005.

Corominas, J.: The angle of reach as a mobility index for small and large landslides, Can. Geotech. J., 33, 260-271, 1996.

Guanquan, Ch., Jinhua, S., Qingsong, W., and Sining, Ch.: Simulation study on the effect of pre-evacuation time and exit width on evacuation, Chinese Sci. Bull., 51(11), 1381-1388, 2006.

Iovine, G. G. R., Lollino, P., Gariano, S. L., and Terranova, O. G.: Coupling limit equilibrium analyses and real-time monitoring to refine a landslide surveillance system in Calabria (southern Italy), Nat. Hazards Earth Syst. Sci., 10, 2341-2354, doi:10.5194/nhess-10-2341-2010, 2010.

Iverson, R. M.: Landslide triggering by rain infiltration, Water Res., 36, 1897-1910, 2000.
Kappes, M. S., Malet, J.-P., Rematre, A., Horton, P., Jaboyedoff, M., and Bell, R.: Assessment of debris-flow susceptibility at medium-scale in the Barcelonnette Basin, France, Nat. Hazards Earth Syst. Sci., 11, 627-641, doi:10.5194/nhess-11-627-2011, 2011.

Mancini, F., Ceppi, C., and Ritrovato, G.: GIS and statistical analysis for landslide susceptibility mapping in the Daunia area, Italy, Nat. Hazards Earth Syst. Sci., 10, 1851-1864, doi:10.5194/nhess-10-1851-2010, 2010.

Marrero, J. M., García, A., Llinares, A., Rodríguez-Losada, J. A., and Ortiz, R.: The Variable Scale Evacuation Model (VSEM): a new tool for simulating massive evacuation processes during volcanic crises, Nat. Hazards Earth Syst. Sci., 10, 747-760, doi:10.5194/nhess-10-747-2010, 2010.

Scotto di Santolo, A., Pellegrino, A. M., and Evangelista, A.: Experimental study on the rheological behaviour of debris flow, Nat. Hazards Earth Syst. Sci., 10, 2507-2514, doi:10.5194/nhess-10-2507-2010, 2010.

Sen, G. and Akyol, E.: A genetic-algorithm approach for assessing the liquefaction potential of sandy soils, Nat. Hazards Earth Syst. Sci., 10, 685-698, doi:10.5194/nhess-10-685-2010, 2010.

Tselentis, G.-A., Stavrakakis, G., Sokos, E., Gkika, F., and Serpetsidaki, A.: Tsunami hazard assessment in the Ionian Sea due to potential tsunamogenic sources - results from numerical simulations, Nat. Hazards Earth Syst. Sci., 10, 1021-1030, doi:10.5194/nhess-10-1021-2010, 2010.

Vieira, B. C., Fernandes, N. F., and Filho, O. A.: Shallow landslide prediction in the Serra do Mar, São Paulo, Brazil, Nat. Hazards Earth Syst. Sci., 10, 1829-1837, doi:10.5194/nhess-101829-2010, 2010. 